WINPEC Working Paper Series No.E2007

July 2020

Hostility toward breaching restrictions during

the COVID-19 pandemic

Ryo Takahashi and Kenta Tanaka

Waseda INstitute of Political EConomy

Waseda University

Tokyo, Japan 


\title{
Hostility toward breaching restrictions during the COVID-19 pandemic
}

\author{
Ryo Takahashi ${ }^{a^{*}}$ and Kenta Tanaka ${ }^{b}$ \\ ${ }^{a}$ Waseda University, Graduate School of Economics, 1-6-1 Nishi-Waseda, Tokyo Japan \\ ${ }^{\mathrm{b}}$ Musashi University, Faculty of Economics, 1-26-1 Toyotamakami, Tokyo Japan
}

\begin{abstract}
Given the outbreak of Covid-19 most countries have adopted prevention policies that restrict economic and social activities to curb the spread. This has led to increased vigilantism and violence; for instance, Japan reported many cases of stores and firms experiencing harassment for breaching the restrictions during the state of emergency. Accordingly, this study empirically investigates the hostility toward the violation of restriction policy (breaching behavior) by stores in Japan and provides policy suggestions for efficient strategies to reduce the hostility level. We conducted an online randomized experiment of 1,600 individuals in Japan and measured their level of hostility by implementing joy-of-destruction minigames. Our results suggest that participants' average level of hostility toward industries that breach restrictions increased by $29 \%$. However, after providing information on guideline adherence for preventing COVID-19 and sending moral suasion messages, participants significantly reduced their hostility level by $19 \%$ and $15 \%$, respectively. Both interventions successfully reduced the probability of the most harmful behavior by approximately 8 percentage points.
\end{abstract}

Keywords: hostility, online randomized experiment, COVID-19, Japan

JEL codes: C91, D91

\footnotetext{
* Corresponding author

E-mail addresses: ryo@waseda.jp (R. Takahashi),k-tanaka@cc.musashi.ac.jp (K. Tanaka).
} 


\section{Introduction}

The novel coronavirus disease (COVID-19) has rapidly spread worldwide, with over 9.5 million reported cases as of June 26, 2020 (World Health Organization, 2020). Thus, to prevent the crisis from escalating further, most countries have adopted stringent policies that restrict economic and social activities, such as the shutdown of national borders, limits on recreational and cultural activities, and temporary business and school closures. Several empirical studies have confirmed that the implementation of stringent restrictions effectively flattens the pandemic curve (Chinazzi et al., 2020; Deb et al., 2020; Kraemer et al., 2020; Tian et al., 2020).

Although the restriction policies are implemented to save lives, they are highly disruptive to society, economically and socially. One outcome is that people perceive vigilantism as acceptable during a pandemic (Di Salvo and Milan, 2020). For example, in the US, armed vigilante bands are reported to have blocked their neighbors from leaving home since the neighbors were suspected of having COVID-19 (Srikanth, 2020). The conflicts between the restriction-justified group and the anti-restriction group are widely observed in the US (Dyer, 2020). Moreover, Mehrotra (2020) empirically investigates that the probability of COVID-19-related conflict has increased in India, while religious conflict and public protests are on the decline. Several social conflicts and hatred between groups with different social identities (even if not explicitly due to vigilantism) have been reported during pandemic circumstance (Bradbury-Jones and Isham, 2020; DeBruin et al., 2012; Mukherjee, 2007).

In the case of Japan, "coronavirus vigilantes" have been socially recognized; they are dubbed as the "self-restraint police." After the COVID-19 outbreak in Japan, the "self-restraint police" have been reported to harass those in breach of COVID-19 restrictions (The Japan Times, 2020). A typical example is the harassment of stores or firms that continue business 
operations despite the COVID-19 state of emergency. However, unlike other countries that implement enforced restrictions (e.g., Australia, China, India, Italy, New Zealand, and the US), the Japanese government adopts a voluntary restriction policy because the domestic emergency law does not allow the government to enforce any restrictions, even temporary business closures (Tashiro and Shaw, 2020). However, the "self-restraint police" have applied hostility and aggression to those they accuse as "implicit social rule-breakers" (hereafter, "rule-breakers") without legal justification. In the situation where the risk of a global second wave of infections is high (Leung et al., 2020; $\mathrm{Xu}$ and Li, 2020), it is important to empirically understand the hostility toward the breach of restrictions during the COVID-19 pandemic.

This study empirically investigates the hostility toward the breach of restrictions during the COVID-19 pandemic and presents policy implications regarding efficient strategies to reduce the hostility level. To measure the level of hostility, we conducted a joy-of-destruction (JoD) experiment of 1,600 individuals in Japan. Participants decided on whether to reduce ("burn") donations to specific industries affected by the pandemic at a personal cost. Since the donation destination is anonymous and randomly chosen from multiple industries, the experimental setup removes the potential motivation for money-burning behavior, such as inequity aversion, envy, and social reputation building (Prediger et al., 2014). Thus, in a narrow interpretation, the money-burning expenditure indicates antisocial attitudes, such as hostility.

To measure the hostility toward a restriction breach, we randomly divided the participants into four groups and changed the donation scenario. To the participants in one group, we explained that the donation is given to a store (anonymous) that continued business operation (rule-breaker). The participants in another group played the JoD minigame against a store that temporarily closed during the emergency periods. Hence, we can estimate the average hostility level by comparing the money-burning expenditures between those two groups.

Moreover, to identify the efficient strategies to reduce the hostility level, we 
implemented two types of random interventions: (1) providing guideline adherence information for COVID-19 prevention, established by industry associations; and (2) sending moral suasion messages. After the COVID-19 outbreak, many industry associations established the guidelines for COVID-19 prevention to continue business operations. By randomly providing such information regarding the store to receive the donations, we evaluate the impact of information provision on money-burning decisions. Moreover, we empirically investigate the effect of moral suasion messages on the level of hostility.

Our results suggest that the average level of hostility toward the store that breach restrictions increased by $29 \%$. However, after providing both guideline adherence and moral suasion interventions, the participants significantly reduced their hostility level by $19 \%$ and $15 \%$, respectively. Particularly, both interventions successfully reduced the probability of the most harmful behavior by approximately 8 percentage points.

\section{COVID-19 outbreak and restriction policies in Japan}

Since March 2020, the number of COVID-19 infectious cases has gradually increased in Japan. Thus, to prevent the spread of COVID-19, the Japanese government declared a state of emergency from April 4 to March 25 (Figure 1). However, stringent restrictions, such as the city lockdown, a gathering ban, and temporary business closures, have no legal basis under Japanese emergency law. Thus, the national and local governments adopted two voluntary approaches for COVID-19: (1) a voluntary request to stay at home and (2) a voluntary request for temporary business closures. Particularly, various businesses are subject to a temporary business closure request. Industries considered essential, such as hospitals, transportation services, delivery services, and grocery stores, are the exceptions. 


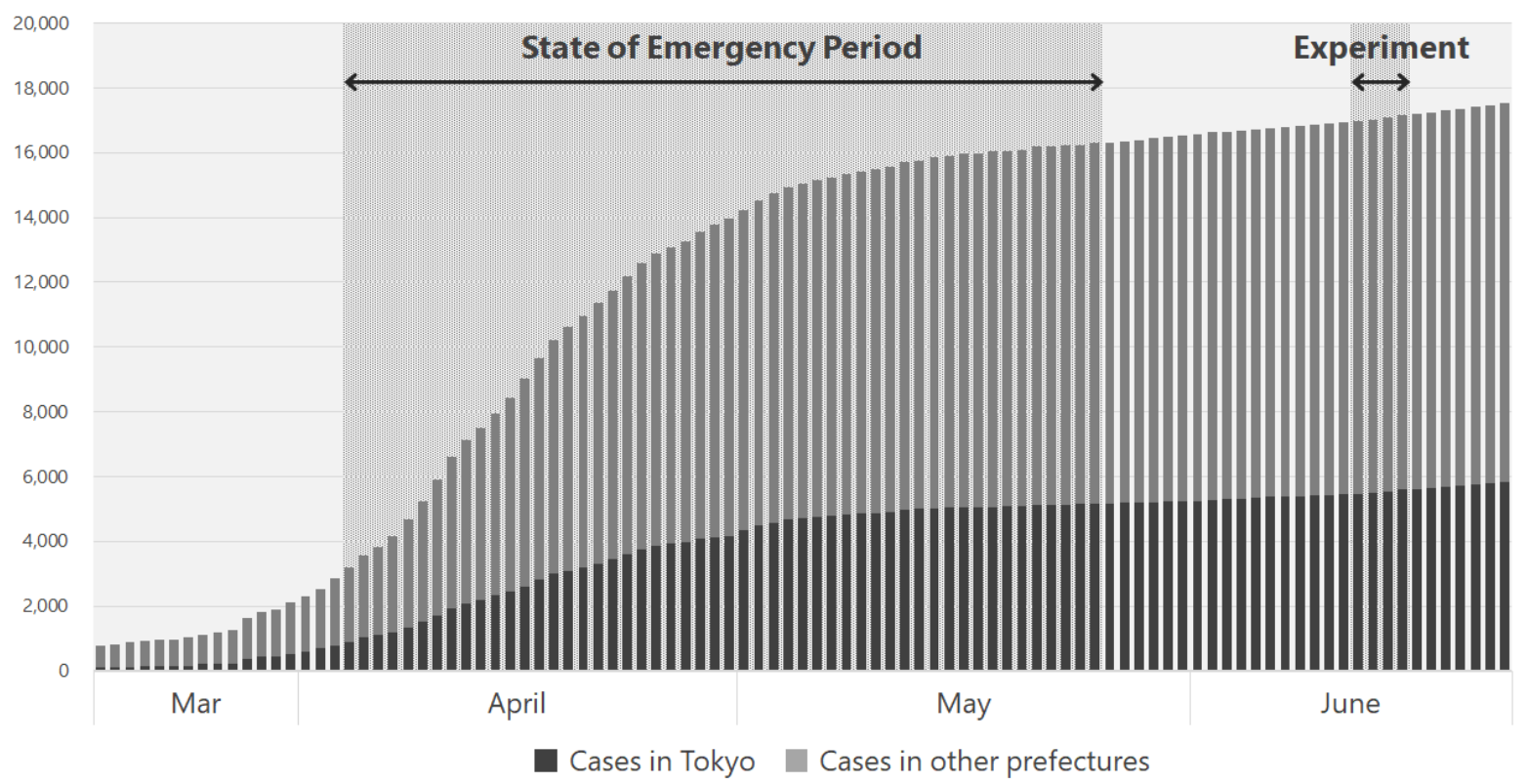

Figure 1. Cumulative COVID-19 cases in Japan and the timing of the state of emergency declaration and data collection

Data source: Ministry of Health, Labour, and Welfare of Japan

These requests are purely voluntary. Thus, adhering to the stay-at-home and temporal closure decision is a personal decision. However, the requests successfully encouraged many people and firms to adhere to the restrictions. For example, social mobility in Tokyo during the requested period drastically declined by approximately $60 \%$ during the weekday and $80 \%$ during the weekend (the Canon Institute for Global Studies, 2020). Notably, the harassment against stores and firms that breach the restrictions has become socially recognized during the emergency periods.

\section{Experimental design and data collection}

After a 17-day interval from the end of the state of emergency (March 25), we conducted the online randomized experiment between June 12 and 15, targeting 1,600 individuals in Japan. The experiment consisted of two tasks: (1) an individual questionnaire survey, and (2) a joy-ofdestruction minigame. 


\subsection{The joy-of-destruction experiment}

The JoD minigame analytically measures antisocial or conflict behavior by estimating a willingness to harm others at an own cost (Abbink and Herrmann, 2011; Abbink and Sadrieh, 2009; Prediger et al., 2014). In this experiment, the participants are initially endowed with 100 Japanese yen, besides the participation allowance of 35 yen. ${ }^{1}$ Prior to the JoD experiment, the participants are informed that the research team will donate 500 yen per participant (equivalent to US\$4.7) to an anonymous store that is negatively affected by the COVID-19 pandemic. ${ }^{2}$ The participants must decide whether to reduce ("burn") the donation amount by 100 yen at a personal cost of 20 yen. Thus, participants can spend all their endowment amount, reducing it to zero. They can also choose to keep 100 yen by choosing not to reduce the donation. The study only considers money-burning expenses from 20 yen to 100 yen by 20 yen intervals (i.e., the money-burning choices are $0,20,40,60,80$, and 100 yen). ${ }^{3}$

Although the store that receives the donations is not disclosed to the participants, we indicated that the donation destination is randomly selected from five industries: (1) the pinball gambling (Pachinko) industry, (2) the foodservice industry with alcohol delivery, (3) the foodservice industry without alcohol delivery, (4) the live music industry, and (5) the retail grocery industry. Participants played the JoD minigames five times and chose money-burning decisions for each industry, given that they have 100 yen available to use for destroying the donation for each industry each time they play. ${ }^{4}$ After the experiment, one money-burning decision from the five minigames was randomly selected. Moreover, based on the selected decision, the endowment amount is given to each participant after the experiment. ${ }^{5}$

\footnotetext{
100 yen and 35 yen are approximately US\$0.9 and US\$0.3, respectively.

The total donation amount after the experiment was 535,200 Japanese yen.

3 Participants cannot increase the donation amount by using their endowment.

4 The order of the industry for the JoD experiment is randomized.

Although the participants can identify the endowment amount after the experiment, the selected industry for the donation is not explicitly disclosed.
} 
We expect that the participants are more likely to reduce the donation amount for the pinball gambling and live music industries because these two industries are frequently criticized as high-risk areas for the spread of COVID-19. We include foodservice industries with and without alcohol delivery since their sales were severely affected due to the stay-at-home request. The retail grocery industry is included as a comparison industry and not because of the temporary business closure request.

In the JoD experiment, the participants did not receive any monetary benefits by reducing the donation. Thus, the rational strategy of the JoD experiment is "not burning" for all five minigames. Therefore, if participants decide to burn their donation at a personal cost, we define the expenditure from the money-burning as a proxy of the hostility level. In this experimental setting, since the store that receives the donation is anonymous and the donation destination is randomly chosen from five industries after the experiment, the motivation for money-burning may not stem from inequity aversion or envy (Prediger et al., 2014).

\subsection{Random interventions}

This study primarily evaluates hostility toward the breach of restrictions and identifies how to reduce its level. Thus, we randomly classified participants into four groups and provide different scenarios during the JoD experiment. In the first group (the "breach group"), participants decided the money-burning expenditure for the store that continued to operate during the state of emergency. In practice, such stores were regarded as rule-breakers.

For the second and third groups, we asked participants whether they would reduce the donation for the store breached the restrictions. However, participants in the second and third groups received the additional guideline adherence information and moral suasion messages, respectively. The participants in the second group (the "guideline group") were informed that even though the store that received donations did not refrain from business operation, it 
followed the guidelines for COVID-19 prevention. To continue business operations after the COVID-19 outbreak, many industry associations established the COVID-19 prevention guidelines (e.g., handwashing with soap, disinfecting, wearing masks, and social distancing). We expect that providing such information may help participants appreciate that the store does not break the "guideline rule," thus reducing hostility toward the breach of restrictions.

Furthermore, we send moral suasion messages to participants in the third group (the "moral suasion group"). A primary reason for continuing the business operations during the state of emergency is the tradeoffs between economic benefits and temporary business closure. Enterprises may not accept the temporary business closure request if the risk of bankruptcy is practically high. In the moral suasion group, messages to participants informed them that the store might suffer bankruptcy by following the temporary business closure request. Reminding participants of the economic tradeoffs therein may reduce their hostility through moral suasion.

Finally, in the fourth group (the "control group"), the participants played the JoD minigame against the store that suspended business operations during the state of emergency. Since the donated store for the control group fully cooperated with the temporary business closure request, there should be no hostility related to a breach of restriction. Therefore, by comparing the hostility level between the breach and control groups, we can examine the hostility toward the breach of restriction during the COVID-19 pandemic.

\subsection{Participants}

We recruited 1,600 individuals nearly throughout Japan (except for one prefecture) via an online survey company (Figure A1 of Appendix A). Table 1 presents the average demographic characteristics of participants at the group level. Since we conducted the initial screening by gender, the proportion of female participants is exactly $50 \%$ for each group. Although there is no-screening by nationality, $99.7 \%$ of participants are Japanese. 
Table 1. Average demographic characteristics

\begin{tabular}{lclllc}
\hline & $\begin{array}{l}\text { Group 1 } \\
\text { (Breach) }\end{array}$ & $\begin{array}{l}\text { Group 2 } \\
\text { (Guideline) }\end{array}$ & $\begin{array}{l}\text { Group 3 } \\
\text { (Moral } \\
\text { suasion) }\end{array}$ & $\begin{array}{l}\text { Group 4 } \\
\text { (Control) }\end{array}$ & Total \\
& $(1)$ & $(2)$ & $(3)$ & $(4)$ & $(5)$ \\
\hline Number of observations & 400 & 400 & 400 & 400 & 1,600 \\
Female (\%) & 50 & 50 & 50 & 50 & 50 \\
Demographic characteristics & & & & & \\
\hline Age & 44.822 & 44.873 & 45.125 & 44.818 & 44.909 \\
Number of household & $(14.017)$ & $(13.968)$ & $(14.057)$ & $(14.075)$ & $(14.017)$ \\
members & 2.663 & 2.815 & 2.768 & 2.732 & 2.744 \\
Proportion of members aged & $(1.201)$ & $(1.332)$ & $(1.367)$ & $(1.283)$ & $(1.297)$ \\
over 60 & 0.235 & 0.231 & 0.233 & 0.229 & 0.232 \\
Proportion of members aged & $(0.341)$ & $(0.331)$ & $(0.326)$ & $(0.332)$ & $(0.332)$ \\
under 10 & 0.070 & 0.067 & 0.057 & 0.061 & 0.064 \\
University-graduate dummy & $(0.159)$ & $(0.154)$ & $(0.143)$ & $(0.154)$ & $(0.152)$ \\
High-income dummy (over & 0.443 & 0.463 & 0.438 & 0.465 & 0.452 \\
10M yen) & $(0.497)$ & $(0.499)$ & $(0.497)$ & $(0.499)$ & $(0.498)$ \\
Initial level of social norms & 0.085 & 0.105 & 0.118 & 0.108 & 0.104 \\
Political follower dummy & $(0.279)$ & $(0.307)$ & $(0.322)$ & $(0.310)$ & $(0.305)$ \\
& -0.071 & 0.008 & 0.006 & 0.056 & 0.000 \\
& $(1.021)$ & $(0.989)$ & $(1.001)$ & $(0.988)$ & $(1.000)$ \\
& 0.190 & 0.193 & 0.168 & 0.150 & 0.175 \\
& $(0.393)$ & $(0.395)$ & $(0.374)$ & $(0.358)$ & $(0.380)$
\end{tabular}

Effect of the COVID-19 pandemic

\begin{tabular}{lccccc}
\hline Personal relationship dummy & 0.037 & 0.015 & 0.035 & 0.022 & 0.028 \\
& $(0.190)$ & $(0.122)$ & $(0.184)$ & $(0.148)$ & $(0.164)$ \\
Follow the stay-at-home & 0.623 & 0.658 & 0.600 & 0.578 & 0.614 \\
request during a state of & $(0.485)$ & $(0.475)$ & $(0.491)$ & $(0.495)$ & $(0.487)$ \\
emergency & & & & & \\
Psychological stress of & 1.350 & 1.335 & 1.350 & 1.337 & 1.343 \\
COVID-19 & $(0.930)$ & $(0.935)$ & $(0.889)$ & $(0.878)$ & $(0.907)$ \\
Monthly income change in & -0.100 & -0.109 & -0.110 & -0.099 & -0.104 \\
April & $(0.239)$ & $(0.230)$ & $(0.214)$ & $(0.212)$ & $(0.224)$ \\
\hline
\end{tabular}


The average demographic characteristics of participants are similar to the national average of Japan. For example, the average age and the number of household members of participants are, respectively, 44.9 years and 2.7 members, as compared to 46.4 years and 2.4 for the national average obtained from the data of population census in 2015 (Statistical Bureau, 2015). In our data, approximately $10 \%$ of the participants receive an annual income of over 10 million yen (equivalent to US\$93 thousand). Moreover, in 2018, the proportion of people with an annual income of over 10 million yen is approximately $12 \%$ (Ministry of Health, Labour, and Welfare, 2018).

To construct the indicator related to the initial level of social norms before the JoD minigame, we conducted a principal component analysis using 10 questions that assess the antisocial behavior perceptions of participants (e.g., not using impolitely to the elderly, talking on mobile phones in a train or bus, and not participating in community's event). The indicator of the initial level of social norms is expected to capture the pre-trend of participants' attitudes toward social norms.

Moreover, we constructed a political follower dummy variable. Two major motivations for money-burning behavior toward stores that breach restrictions are as follows. The first stems from hostility toward the breach of restrictions, which is the primary interest of this study. The second stems from the political belief that individuals should follow government requests in any circumstances. To distinguish between two motivations, we constructed a political follower dummy, which takes 1 if the participant strongly believes that people should follow the government's policy. The summary statistics indicate that approximately $17.5 \%$ of participants are political followers.

During the questionnaire survey, we asked questions related to the influence of the pandemic in Japan. The personal relationship dummy takes 1 if the participant has a personal relationship with a COVID-19 positive patient (i.e., relative or friend). Table 1 shows that, on 
average, only $2.8 \%$ of participants personally know an infected person. Moreover, $61.4 \%$ of the participants reported that they strictly followed the stay-at-home request and self-quarantined.

The psychological stress of the COVID-19 pandemic is evaluated in four scale steps from 0 (no stress) to 3 (acute stress). The average stress scores were 1.3, while those without any psychological stress were only 17\%. Regarding the economic impact of the COVID-19 pandemic, we measured the monthly income changes in April when the entire Japanese economy was substantially affected. Notably, the economic performance index published by the Cabinet Office of Japan drastically dropped from 14.2 in March to 7.9 in April and recovered by climbing to 15.5 in May. The participants reported that the monthly income in April declined by approximately $10 \%$, as compared to the previous year.

Finally, we compared the average of each indicator in Table 1 by using the Scheffe's multiple comparison test and found no statistical differences between the four groups.

\section{Estimation methodology}

To identify the hostility toward the breach of restrictions and the effect of interventions, we start with a prefecture-level fixed effects regression model, which is specified as follows:

$\log$ Burn $_{i j}=\alpha+\beta_{1}$ Guideline $_{i}+\beta_{2}$ Moral $_{i}+\beta_{3}$ Control $_{i}+\gamma$ Industry $_{j}+\delta X_{i}+\rho_{i}+\varepsilon_{i j}$,

where $\log B u r n_{i j}$ is the natural logarithm of the money-burning expenditure on industry $j$ for individual $i$. Guideline ${ }_{i}$ and Moral $_{i}$ are dummy variables that take 1 if individual $i$ receives, respectively, the guideline adherence information and moral suasion messages. Control $_{i}$ denotes whether individual $i$ belongs to the control group (i.e., group 4). $X_{i}$ is a set of observable characteristics of individual $i$, which are shown in Table 1. $\rho_{i}$ represents the prefecture-specific 
fixed effects for individual $i$, which reduces the unobserved time-invariant differences between prefectures. Standard errors are clustered at the group and industry level to account for autocorrelations in the error term $\varepsilon_{i t}$. Table B1 of Appendix B presents the description of the independent variables.

In equation 1, we excluded the dummy variable for group 1, where participants may be more hostile than the three other groups. Therefore, the $\beta \mathrm{s}$ in equation 1 are expected to be negative values. More precisely, $\beta_{1}$ and $\beta_{2}$ in equation 1 measure the average impact of each intervention on hostility toward the breach of restrictions, while $\beta_{3}$ indicates the general hostility.

To further investigate the determinants of individual money-burning decisions, we employ a multinomial logistic model:

$$
\operatorname{Prob}\left(J o D_{i j}=k\right)=\frac{\exp \left(\theta^{\prime}{ }_{k} Z_{i}+\gamma^{\prime}{ }_{k} \text { Industry } y_{j}\right)}{1+\sum_{k=0}^{5} \exp \left(\theta^{\prime}{ }_{k} Z_{i}+\gamma_{k}^{\prime}{ }_{k} \text { Industry } y_{j}\right)}
$$

where $J o D_{i j}$ represents the money-burning decisions to industry $j$ for individual $i$ : 0 yen $(k=0)$, 20 yen $(k=1), 40$ yen $(k=2), 60$ yen $(k=3), 80$ yen $(k=4)$, or 100 yen $(k=5)$. We assume $\theta_{0}$ and $\gamma^{\prime}{ }_{0}$ for normalization. $Z_{i j}$ is a set of variables, including the group dummies (i.e., Guideline and Moral, and Control in equation 1), the observable characteristics (X), and the prefecturespecific fixed effects. The marginal effects are estimated to estimate the probability of moneyburning decisions. ${ }^{6}$

\section{Results}

\footnotetext{
6 The marginal effects estimated from the multinomial logistic model indicates the probability of each moneyburning decision, not the effect on the money-burning expenditures.
} 


\subsection{Results of the joy-of-destruction experiment}

The results of the JoD minigame (Table 2) indicated that the participants spend approximately 33.6 yen (US\$0.3) to reduce donations at a personal cost. As expected, the average money-burning expenditure of group 1 ( 38.1 yen) is statistically larger than that of the three other groups. Particularly, the average money-burning expenditures for pinball gambling and small-scale live music club were larger than 40 yen for group 1 participants. Appendix C reports the relationship between money-burning behavior and the COVID-19 outbreak at the prefecture level.

Table 2. Average money-burning expenditures by industry

\begin{tabular}{lccccc}
\hline & $\begin{array}{c}\text { Group1 } \\
\text { (Breach) }\end{array}$ & $\begin{array}{c}\text { Group 2 } \\
\text { (Guideline) }\end{array}$ & $\begin{array}{c}\text { Group 3 } \\
\text { (Moral } \\
\text { suasion) }\end{array}$ & $\begin{array}{c}\text { Group 4 } \\
\text { (Control) }\end{array}$ & Total \\
& $(1)$ & $(2)$ & $(3)$ & $(4)$ & $(5)$ \\
\hline Pinball gambling (Pachinko) & $42.55^{\mathrm{a}}$ & 37.35 & 36.50 & $32.75^{\mathrm{a}}$ & 37.29 \\
& $(45.47)$ & $(43.76)$ & $(43.02)$ & $(42.01)$ & $(43.68)$ \\
Foodservice with alcohol & 38.05 & 31.95 & 33.45 & 31.65 & 33.78 \\
delivery & $(42.35)$ & $(38.63)$ & $(38.96)$ & $(39.26)$ & $(39.87)$ \\
Foodservice without alcohol & 35.35 & 32.00 & 30.05 & 31.55 & 32.24 \\
delivery & $(40.86)$ & $(38.26)$ & $(36.79)$ & $(39.03)$ & $(38.77)$ \\
Small-scale live music club & $41.25^{\mathrm{abc}}$ & $31.60^{\mathrm{a}}$ & $32.45^{\mathrm{b}}$ & $29.10^{\mathrm{c}}$ & 33.60 \\
& $(43.82)$ & $(39.41)$ & $(40.10)$ & $(39.10)$ & $(40.87)$ \\
Grocery store & 33.20 & 29.15 & 29.50 & 31.65 & 30.88 \\
& $(41.47)$ & $(37.77)$ & $(37.91)$ & $(39.84)$ & $(39.28)$ \\
\hline Total & $38.08^{\mathrm{abc}}$ & $32.41^{\mathrm{a}}$ & $32.39^{\mathrm{b}}$ & $31.34^{\mathrm{c}}$ & 33.56 \\
& $(42.93)$ & $(39.68)$ & $(39.45)$ & $(39.84)$ & $(40.60)$ \\
\hline
\end{tabular}

Note: Standard deviations are in parentheses.

a, b, c superscript letters indicate statistically significant differences between the groups at the $5 \%$ level, based on the Scheffe's multiple comparison test.

\subsection{Estimation results of linear regression}

The first column of Table 3 shows the estimation results of equation 1, while columns 
2 and 3 present the results without the characteristics of the participant and the prefecture fixed effects. First, the control group dummy negatively affected money-burning expenditures, which indicates the general hostility toward the breach restrictions. The coefficient indicates that people significantly increase hostility toward rule-breakers by $29 \%$.

Table 3. Effect of the guideline adherence and moral suasion on money-burning expenditures

\begin{tabular}{|c|c|c|c|}
\hline & (1) & (2) & (3) \\
\hline \multirow[t]{2}{*}{ Guideline group dummy } & $-0.192 * * *$ & $-0.193 * * *$ & $-0.167 * * *$ \\
\hline & $(0.056)$ & $(0.055)$ & $(0.058)$ \\
\hline \multirow[t]{2}{*}{ Moral suasion group dummy } & $-0.147 * *$ & $-0.137 * *$ & $-0.149 * *$ \\
\hline & $(0.052)$ & $(0.055)$ & $(0.054)$ \\
\hline \multirow[t]{2}{*}{ Control group dummy } & $-0.290 * * *$ & $-0.282 * * *$ & $-0.263 * * *$ \\
\hline & $(0.069)$ & $(0.071)$ & $(0.070)$ \\
\hline \multirow[t]{2}{*}{ Industry dummy: Pinball gambling } & $0.153^{* *}$ & $0.153^{* *}$ & $0.153^{* *}$ \\
\hline & $(0.068)$ & $(0.068)$ & $(0.068)$ \\
\hline \multirow[t]{2}{*}{ Industry dummy: With Alcohol } & $0.196^{* * *}$ & $0.196^{* * *}$ & $0.196^{* * *}$ \\
\hline & $(0.059)$ & $(0.059)$ & $(0.059)$ \\
\hline \multirow[t]{2}{*}{ Industry dummy: Without Alcohol } & $0.179 * *$ & $0.179 * *$ & $0.179 * *$ \\
\hline & $(0.064)$ & $(0.064)$ & $(0.064)$ \\
\hline \multirow[t]{2}{*}{ Industry dummy: Live music club } & 0.091 & 0.091 & 0.091 \\
\hline & $(0.079)$ & $(0.079)$ & $(0.078)$ \\
\hline \multirow[t]{2}{*}{ Female dummy } & 0.079 & & $0.086^{*}$ \\
\hline & $(0.046)$ & & $(0.046)$ \\
\hline \multirow[t]{2}{*}{ Age } & $0.012 * * *$ & & $0.013 * * *$ \\
\hline & $(0.001)$ & & $(0.001)$ \\
\hline \multirow[t]{2}{*}{ Number of household members } & 0.019 & & -0.000 \\
\hline & $(0.018)$ & & $(0.020)$ \\
\hline \multirow[t]{2}{*}{ Proportion of members aged over 60} & -0.077 & & -0.091 \\
\hline & $(0.085)$ & & $(0.094)$ \\
\hline \multirow[t]{2}{*}{ Proportion of members aged under 10} & $0.440 *$ & & $0.443 * *$ \\
\hline & $(0.213)$ & & (0.199) \\
\hline \multirow[t]{2}{*}{ University-graduate dummy } & 0.076 & & 0.068 \\
\hline & $(0.062)$ & & $(0.063)$ \\
\hline
\end{tabular}


(Table 3 continued)

\begin{tabular}{|c|c|c|c|}
\hline High-income dummy & $\begin{array}{l}-0.141 \\
(0.087)\end{array}$ & & $\begin{array}{l}-0.124 \\
(0.085)\end{array}$ \\
\hline Initial level of social norms & $\begin{array}{l}0.132 * * * \\
(0.038)\end{array}$ & & $\begin{array}{l}0.128 * * * \\
(0.036)\end{array}$ \\
\hline Political follower dummy & $\begin{array}{l}-0.071 \\
(0.046)\end{array}$ & & $\begin{array}{l}-0.071 \\
(0.043)\end{array}$ \\
\hline Personal relationship dummy & $\begin{array}{l}0.461 * * * \\
(0.111)\end{array}$ & & $\begin{array}{l}0.502 * * * \\
(0.113)\end{array}$ \\
\hline Stay-at-home dummy & $\begin{array}{l}-0.110 * * \\
(0.045)\end{array}$ & & $\begin{array}{l}-0.105 * * \\
(0.044)\end{array}$ \\
\hline Psychological stress of COVID-19 & $\begin{array}{l}0.006 \\
(0.037)\end{array}$ & & $\begin{array}{l}0.011 \\
(0.034)\end{array}$ \\
\hline Monthly income change in April & $\begin{array}{l}-0.122 \\
(0.105)\end{array}$ & & $\begin{array}{l}-0.134 \\
(0.102)\end{array}$ \\
\hline Constant & $\begin{array}{l}1.091 * * * \\
(0.092)\end{array}$ & $\begin{array}{l}1.717 * * * \\
(0.076)\end{array}$ & $\begin{array}{l}1.098 * * * \\
(0.098)\end{array}$ \\
\hline Prefecture fixed effect & YES & YES & No \\
\hline Observations & 8,000 & 8,000 & 8,000 \\
\hline R-squared & 0.037 & 0.026 & 0.014 \\
\hline Mean of JoD & 33.56 & & \\
\hline
\end{tabular}

Note: Standard errors are clustered at group and industry level in parentheses; $*, * *$, and $* * *$ indicate statistical significance at the $10 \%, 5 \%$, and $1 \%$ levels, respectively.

We expected the guideline adherence information and moral suasion messages to negatively affect money-burning behavior via a change in perception and appreciation of the economic tradeoffs. The results show that both intervention dummies significantly reduce hostility by $19 \%$ and $15 \%$, respectively. By comparing the estimated coefficient of the intervention dummies and control dummy, the results suggest that people become hostility at 10 to 14 percentage points even after receiving the guideline adherence information and moral suasion messages. However, the level of hostility is successfully alleviated through the interventions.

Some may argue that the money-burning decisions are due to serious concerns regarding 
the spread of COVID-19, not hostility toward the breach of restrictions. However, if the concern over the disease is an actual motivation, we should not observe the reduction effect through the moral suasion messages since it has no effect on such a concern. Moral suasion messages exhibited a reduction effect on hostility at a similar magnitude as that of the guideline adherence information. Hence, it is reasonable to conclude that the money-burning expenditures explain the people's hostility toward the breach of restrictions during the pandemic.

\subsection{Determinants of hostile behavior}

We performed the multinomial logistic model to investigate the determinants of the money-burning decisions. Table 4 presents the marginal effects of the results, with columns 1 to 5 showing the results of money-burning decisions from 20 yen to 100 yen by 20 yen intervals. Column 5 shows that both intervention dummies significantly reduce the probability of the most harmful money-burning decision (burning all donations) by approximately 8 percentage points. However, the interventions did not curb the probability of the other money-burning decisions (columns 1-4).

Table 4. Determinants of individual money-burning decisions using a multinomial logistic model

\begin{tabular}{lllllc}
\hline $\begin{array}{l}\text { Money-burning expenditures } \\
\text { [Donation amount }]\end{array}$ & $\begin{array}{c}20 \text { yen } \\
{[80 y e n]}\end{array}$ & $\begin{array}{c}40 \text { yen } \\
{[60 y e n]}\end{array}$ & $\begin{array}{c}60 \text { yen } \\
{[40 y e n]}\end{array}$ & $\begin{array}{c}80 \text { yen } \\
{[20 y e n]}\end{array}$ & $\begin{array}{c}100 \text { yen } \\
{[0 \text { yen }]}\end{array}$ \\
\hline Guideline group dummy & $0.039^{* * *}$ & $0.008^{*}$ & $0.005^{*}$ & 0.001 & $-0.076^{* * *}$ \\
& $(0.005)$ & $(0.004)$ & $(0.002)$ & $(0.003)$ & $(0.010)$ \\
Moral Suasion group dummy & $0.047^{* * *}$ & $0.013^{* * *}$ & -0.002 & $0.008^{* *}$ & $-0.078^{* * *}$ \\
& $(0.007)$ & $(0.004)$ & $(0.002)$ & $(0.003)$ & $(0.008)$ \\
Control group dummy & $0.040^{* * *}$ & 0.006 & $-0.007 * * *$ & $-0.006^{* *}$ & $-0.068^{* * *}$ \\
& $(0.008)$ & $(0.004)$ & $(0.002)$ & $(0.003)$ & $(0.013)$ \\
Industry dummy: Pinball & $-0.040^{* * *}$ & $-0.032^{* * *}$ & $-0.004 * *$ & -0.001 & $0.088^{* * *}$ \\
gambling & $(0.006)$ & $(0.006)$ & $(0.002)$ & $(0.003)$ & $(0.012)$
\end{tabular}




\begin{tabular}{|c|c|c|c|c|c|}
\hline \multicolumn{6}{|l|}{ (Table 4 continued) } \\
\hline \multirow[t]{2}{*}{ Industry dummy: With Alcohol } & 0.004 & $0.006^{*}$ & $0.004 * *$ & 0.005 & $0.019 *$ \\
\hline & $(0.003)$ & $(0.003)$ & $(0.002)$ & $(0.003)$ & $(0.010)$ \\
\hline Industry dummy: Without & $0.018 * * *$ & $0.018 * * *$ & 0.002 & 0.000 & 0.004 \\
\hline Alcohol & $(0.007)$ & $(0.003)$ & $(0.002)$ & $(0.003)$ & $(0.013)$ \\
\hline Industry dummy: Live music & $-0.018 * * *$ & -0.002 & 0.000 & 0.003 & $0.031 * *$ \\
\hline club & $(0.007)$ & $(0.004)$ & $(0.003)$ & $(0.003)$ & $(0.014)$ \\
\hline \multirow[t]{2}{*}{ Female dummy } & 0.009 & 0.014 & 0.000 & $0.011 * * *$ & -0.017 \\
\hline & $(0.007)$ & $(0.009)$ & $(0.003)$ & $(0.003)$ & $(0.012)$ \\
\hline \multirow[t]{2}{*}{ Age } & $-0.001 * * *$ & $-0.001 * * *$ & $0.000^{*}$ & 0.000 & $0.004 * * *$ \\
\hline & $(0.000)$ & $(0.000)$ & $(0.000)$ & $(0.000)$ & $(0.000)$ \\
\hline \multirow[t]{2}{*}{ Number of household members } & $0.005^{*}$ & $-0.005 * * *$ & -0.001 & $0.004 * * *$ & 0.002 \\
\hline & $(0.003)$ & $(0.002)$ & $(0.001)$ & $(0.001)$ & $(0.005)$ \\
\hline \multirow{2}{*}{$\begin{array}{l}\text { Proportion of members aged } \\
\text { over } 60\end{array}$} & 0.003 & 0.007 & 0.002 & -0.004 & -0.021 \\
\hline & $(0.008)$ & $(0.009)$ & $(0.003)$ & $(0.004)$ & $(0.017)$ \\
\hline \multirow{2}{*}{$\begin{array}{l}\text { Proportion of members aged } \\
\text { under } 10\end{array}$} & 0.023 & $0.052 * * *$ & $0.018 * *$ & -0.011 & 0.017 \\
\hline & $(0.015)$ & $(0.014)$ & $(0.007)$ & $(0.008)$ & $(0.039)$ \\
\hline \multirow[t]{2}{*}{ University-graduate dummy } & $-0.013 * *$ & $0.019 * * *$ & $0.005^{*}$ & $0.006^{* *}$ & -0.009 \\
\hline & $(0.005)$ & $(0.006)$ & $(0.002)$ & $(0.003)$ & $(0.013)$ \\
\hline \multirow[t]{2}{*}{ High-income dummy } & -0.012 & $-0.025 * * *$ & 0.000 & $-0.009 *$ & 0.011 \\
\hline & $(0.012)$ & $(0.008)$ & $(0.004)$ & $(0.005)$ & $(0.019)$ \\
\hline \multirow[t]{2}{*}{ Initial level of social norms } & $0.019 * * *$ & $0.007 * *$ & $0.002 * *$ & $0.005 * * *$ & -0.004 \\
\hline & $(0.004)$ & $(0.004)$ & $(0.001)$ & $(0.002)$ & $(0.005)$ \\
\hline \multirow[t]{2}{*}{ Political follower dummy } & $-0.013 *$ & 0.005 & -0.003 & $-0.020 * * *$ & $0.018 *$ \\
\hline & $(0.007)$ & $(0.006)$ & $(0.003)$ & $(0.004)$ & $(0.010)$ \\
\hline \multirow[t]{2}{*}{ Personal relationship dummy } & $0.054 * * *$ & -0.014 & 0.006 & 0.005 & 0.049 \\
\hline & $(0.017)$ & $(0.017)$ & $(0.005)$ & $(0.007)$ & $(0.035)$ \\
\hline \multirow[t]{2}{*}{ Stay-at-home dummy } & -0.007 & $-0.039 * * *$ & 0.001 & -0.002 & $0.019 * * *$ \\
\hline & $(0.006)$ & $(0.004)$ & $(0.003)$ & $(0.003)$ & $(0.007)$ \\
\hline Psychological stress of COVID- & $0.014 * * *$ & 0.001 & -0.001 & -0.001 & -0.007 \\
\hline 19 & $(0.003)$ & $(0.003)$ & $(0.001)$ & $(0.002)$ & $(0.006)$ \\
\hline \multirow[t]{2}{*}{ Monthly income change in April } & $0.036 * *$ & 0.010 & $0.008^{*}$ & -0.006 & $-0.059 * * *$ \\
\hline & $(0.015)$ & $(0.012)$ & $(0.004)$ & $(0.004)$ & $(0.018)$ \\
\hline
\end{tabular}

Note: Standard errors are clustered at group and industry level in parentheses; *, **, and, *** indicate statistical significance at the $10 \%, 5 \%$, and $1 \%$ levels, respectively.

Unsurprisingly, the probability of reducing all donations increases for pinball gambling 
and live music club industries, probably because of the negative publicity of their being highrisk areas the COVID-19. Moreover, participants tended to be more hostile toward the foodservice industry with alcohol delivery than that without alcohol delivery.

The probability of the most harmful money-burning decision is associated with several demographic characteristics of the participants, such as the positive association with age, the political follower dummy, and the stay-at-home dummy, as well as the negative association with the monthly income change in April. First, the positive association with age implies that an additional 10-year increase in age increased the probability by approximately 4 percentage points. This result is consistent with prior research findings (Basurto et al., 2016; Saleh, 2020). Second, those who strictly adhered to government requests (political followers) increased the probability by 1.8 percentage points. Meanwhile, the participants who followed the stay-at-home request increased the probability by 1.9 percentage points. Third, the monthly income change in April negatively affected the probability, indicating that a 10-percentagepoint decrease in the monthly income in April increased the probability by 0.6 percentage points. There are two potential explanations for why the participants that experienced a decrease in the monthly income decided not to destroy all donations. First, the incentive to receive the endowment is higher for participants whose economic status is negatively affected by the COVID-19 pandemic. Second, participants affected by income decreases may feel sympathy for breaching industries, thereby deciding not to burn all their donations.

Moreover, other demographic characteristics of the participants were related to the probability of money-burning decisions between 20 yen and 80 yen. For example, the probability of reducing a donation by 40 yen and 60 yen increases with household members who are 10 years old. Meanwhile, there is no statistical relationship with members who are over 60 years old. More precisely, an additional 10 percentage points increase in the proportion of children enhances the money-burning of 40 yen and 60 yen by 0.5 and 0.2 percentage points, 
respectively. The fact that COVID-19 concerns are greater for the participants with young children explains the resulting hostile behavior.

Moreover, university-graduates were more likely to be hostile; they increased the money-burning probability of 40,60 , and 80 yen burning by $1.9,0.5$, and 0.6 percentage points, respectively. However, the money-burning decisions of 40 and 80 yen were suppressed by 2.5 and 0.9 percentage points if the participants received a high annual income, such as an annual income of over 10 million yen. Some empirical studies that employ the JoD experiment also confirmed similar findings (Saleh, 2020; Vorlaufer, 2019). Finally, the initial level of social norms before the experiment is positively associated with the money-burning decision between 20 and 80 yen. These results suggest that participants that value social norms highly become hostile toward the breach of restrictions.

\section{Conclusion}

By conducting the joy-of-destruction experiment of 1,600 individuals in Japan, this study reported the empirical evidence of hostility toward the breach of restrictions, such as not following the temporary business closure request during the COVID-19 state of emergency. We found that the participants increased the average level of hostility toward industries that continued business operations by $29 \%$. Moreover, to identify efficient strategies for reducing the hostility level, we implemented two types of random interventions: (1) providing guideline adherence information for COVID-19 prevention established by industry associations and (2) sending moral suasion messages. The results indicated that both interventions reduced the hostility level by $19 \%$ and $15 \%$, respectively. Particularly, both interventions successfully reduced the probability of the most harmful behavior by approximately 8 percentage points.

This study presents several policy implications. First, to curb hostility under extraordinary circumstances, it is important to establish and advertise guideline adherence. 
After the COVID-19 outbreak in Japan, many industry associations established the COVID-19 prevention guidelines to continue their business activities. Although we are not arguing for the prevention efficiency of the guidelines, the response of industry associations may be appropriate to reduce hostility. Second, individual enterprises may avoid harassment from the "self-restraint police" by publicly sending moral suasion messages to help appreciate the economic tradeoffs in the temporary business closure. Third, to stabilize society during a state of emergency, policymakers should be aware that people with specific demographic characteristics may become hostile toward others. Although Bartscher et al. (2020) indicate that strong social ties could affect the reduction in the spread of COVID-19, our results imply that hostility toward the breach of restrictions among those that appreciate social norms may be substantially large. Hence, it is important to consider hostility prior to implementing prevention policies. 


\section{Acknowledgment}

This paper was supported by JSPS KAKENHI Grant-in-Aid for Scientific Research (B) Number 19H01492. The authors would like to thank K. Suedomi, E. Hama, Y. Kamiya, and H. Kanno, for the help with data collection.

\section{Declaration of competing interest}

The authors declare that they have no known competing financial interests or personal relationships that could have appeared to influence the work reported in this paper. 


\section{References}

Abbink, K., Herrmann, B., 2011. The moral costs of nastiness. Econ. Inquiry 49, 631-633.

Abbink, K., Sadrieh, A., 2009. The pleasure of being nasty. Econ. Letters 105, 306-308.

Bartscher, A.K., Seitz, S., Siegloch, S., Slotwinski, M., Wehrhöfer, N., 2020. Social capital and the spread of Covid-19: Insights from European countries. Covid Econ. 137-190. https://cepr.org/file/9111/download?token=bZKSlyvA

Basurto, X., Blanco, E., Nenadovic, M., Vollan, B., 2016. Integrating simultaneous prosocial and antisocial behavior into theories of collective action. Sci. Adv. 2, e1501220.

Bradbury-Jones, C., Isham, L., 2020. The pandemic paradox: The consequences of COVID-19 on domestic violence. J. Clin. Nurs. 29(13-14), 2047-2049.

Canon Institute for Global Studies, 2020. Visualization of local residents' restraint rates using big data on fluid population: Relationship between the number of people infected and self-restraint (in Japanese).

https://www.canon-igs.org/column/macroeconomics/20200422_6369.html

Chinazzi, M., Davis, J.T., Ajelli, M., Gioannini, C., Litvinova, M., Merler, S., y Piontti, A.P., Mu, K., Rossi, L., Sun, K., 2020. The effect of travel restrictions on the spread of the 2019 novel coronavirus (COVID-19) outbreak. Sci. 368, 395-400.

Deb, P., Furceri, D., Ostry, J.D., Tawk, N., 2020. The economic effects of Covid-19 containment measures. Covid Econ. 32-75.

DeBruin, D., Liaschenko, J., Marshall, M.F., 2012. Social justice in pandemic preparedness. Am. J. Public Health 102, 586-591.

Di Salvo, P., Milan, S., 2020. Four Invisible Enemies in the First Pandemic of the "Datafied Society." Open Democracy 8, 1-7.

Dyer, O., 2020. Covid-19: Trump stokes protests against social distancing measures. British Medical Journal Publishing Group. 
Japan Times, 2020. Japan's 'virus vigilantes' take on rule-breakers and invaders.

https://www.japantimes.co.jp/news/2020/05/13/national/coronavirus-vigilantesjapan/\#.Xv3UfSj7Rwd

Kraemer, M.U., Yang, C.-H., Gutierrez, B., Wu, C.-H., Klein, B., Pigott, D.M., Du Plessis, L., Faria, N.R., Li, R., Hanage, W.P., 2020. The effect of human mobility and control measures on the COVID-19 epidemic in China. Sci. 368, 493-497.

Leung, K., Wu, J.T., Liu, D., Leung, G.M., 2020. First-wave COVID-19 transmissibility and severity in China outside Hubei after control measures, and second-wave scenario planning: A modelling impact assessment. The Lancet 395(10233), 1382-1393. https://doi.org/10.1016/S0140-6736(20)30746-7

Mehrotra, R., 2020. Contagion and conflict: Evidence from India. Covid Econ. 122-140.

Ministry of Health Labour and Welfare, 2018. 2018 Comprehensive Survey of Living Conditions (in Japanese).

https://www.mhlw.go.jp/english/database/db-hss/cslc-index.html

Mukherjee, J.S., 2007. Structural violence, poverty, and the AIDS pandemic. Dev. 50, 115-121.

Prediger, S., Vollan, B., Herrmann, B., 2014. Resource scarcity and antisocial behavior. J. Public Econ. 119, 1-9.

Saleh, L., 2020. A Friend or a Foe in Exile: An Experimental Analysis of Punishment in the Zaatari Refugee Camp in Jordan. Available at SSRN 3594357. http://dx.doi.org/10.2139/ssrn.3594357

Srikanth, A., 2020. Armed neighbors cut down a tree to block man's driveway because they thought he had coronavirus. The Hill.

Statistical Bureau, 2015. 2015 Population Census of Japan (in Japanese).

Tashiro, A., Shaw, R., 2020. COVID-19 Pandemic Response in Japan: What Is behind the Initial Flattening of the Curve? Sustainability 12(13), 5250. 
https://doi.org/10.3390/su12135250

Tian, H., Liu, Y., Li, Y., Wu, C.-H., Chen, B., Kraemer, M.U., Li, B., Cai, J., Xu, B., Yang, Q., 2020. An investigation of transmission control measures during the first 50 days of the COVID-19 epidemic in China. Science 368, 638-642.

Vorlaufer, T., 2019. Effects of double-anonymity on pro-and anti-social behavior: Experimental evidence from a lab in the field. J. Behav. Exp. Econ. 81, 216-225.

World Health Organization, 2020. Coronavirus disease (COVID-19) Situation Report.

Xu, S., Li, Y., 2020. Beware of the second wave of COVID-19. The Lancet 395, 1321-1322. 


\section{Appendix A}

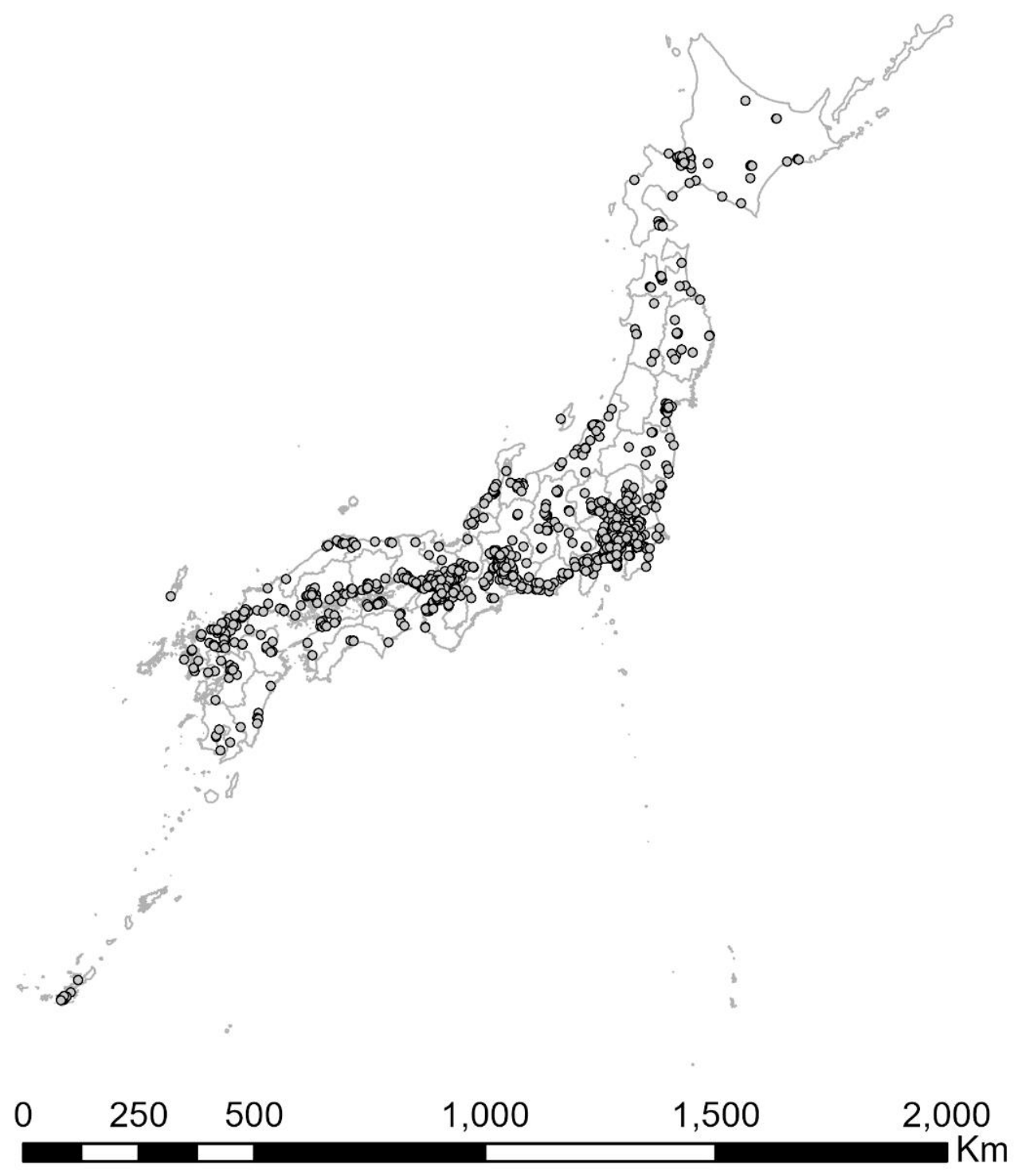

Figure A1. Location of the city where survey participants live 


\section{Appendix B}

Table B1: Description of independent variables

\begin{tabular}{|c|c|}
\hline Variable & Description \\
\hline Guideline group dummy & The participants belong to the guideline group (1=YES) \\
\hline Moral suasion group dummy & The participants belong to the moral suasion group (1=YES) \\
\hline Control group dummy & The participants belong to the control group (1=YES) \\
\hline Industry dummy: Pinball gambling & $\begin{array}{l}\text { Donations are given to stores in the pinball gambling } \\
\text { industry ( } 1=\text { Yes) }\end{array}$ \\
\hline Industry dummy: With Alcohol & $\begin{array}{l}\text { Donations are given to stores in the foodservice industry } \\
\text { with alcohol delivery ( } 1=\text { Yes })\end{array}$ \\
\hline Industry dummy: Without Alcohol & $\begin{array}{l}\text { Donations are given to stores in the foodservice industry } \\
\text { without alcohol delivery ( } 1=\text { Yes })\end{array}$ \\
\hline Industry dummy: Live music club & $\begin{array}{l}\text { Donations are given to stores in the small-scale live music } \\
\text { club industry ( } 1=\text { Yes) }\end{array}$ \\
\hline Female dummy & Gender of the participant ( $1=$ Female $)$ \\
\hline Age & Age of the participants \\
\hline Number of household members & The number of household members of participants \\
\hline Proportion of members aged over 60 & The proportion of members aged over 60 \\
\hline $\begin{array}{l}\text { Proportion of members aged under } \\
10\end{array}$ & The proportion of members aged under 10 \\
\hline University-graduate dummy & The participants graduated from 4-year institutions ( $1=$ Yes) \\
\hline High-income dummy & $\begin{array}{l}\text { The participants receive an annual income of over } 10 \text { million } \\
\text { yen ( } 1=\text { Yes) }\end{array}$ \\
\hline Initial level of social norms & $\begin{array}{l}\text { The indicators of the level of social norms assessed by a } \\
\text { principal component analysis }\end{array}$ \\
\hline Political follower dummy & $\begin{array}{l}\text { The participants believe that people should follow the } \\
\text { government's policy ( } 1=\text { Yes) }\end{array}$ \\
\hline Personal relationship dummy & $\begin{array}{l}\text { Having a personal relationship with a COVID-19 positive } \\
\text { patient ( } 1=\text { Yes) }\end{array}$ \\
\hline Stay-at-home dummy & $\begin{array}{l}\text { The participants follow the stay-at-home requests during the } \\
\text { emergency periods ( } 1=\text { Yes) }\end{array}$ \\
\hline Psychological stress of COVID-19 & $\begin{array}{l}\text { The psychological stress of the COVID-19 pandemic in four } \\
\text { scale steps from } 0 \text { (no stress) to } 3 \text { (acute stress) }\end{array}$ \\
\hline Monthly income change in April & $\begin{array}{l}\text { The changes in monthly income in April, as compared to the } \\
\text { previous year }\end{array}$ \\
\hline
\end{tabular}




\section{Appendix C}

To examine the association between the money-burning behavior and the COVID-19 outbreak at the prefecture level, we obtained the cumulative COVID-19 cases and rates per 100,000 people on June 12 (one day before the experiment) at the prefecture level from the Ministry of Health, Labour, and Welfare. The result is illustrated via the map in Figure C1. Maps (A) and (B) in Figure C2 indicates the average expenditures from the burning by prefecture and city, respectively. Moreover, maps (A) and (B) in Figure C3 presents the average expenditures from the burning in metropolitan areas, such as Tokyo and Osaka.

Table $\mathrm{C} 1$ reports the correlation between the expenditures from the money-burning and COVID-19 cases. Except for restaurants without alcohol delivery, there is a positive correlation between the money-burning expenditures and cumulative COVID-19 cases. Moreover, the average money-burning expenditures is positively associated with the cumulative COVID-19 rates per 100,000 people for three industries: restaurants with alcohol delivery, small-scale live music clubs, and grocery stores. 


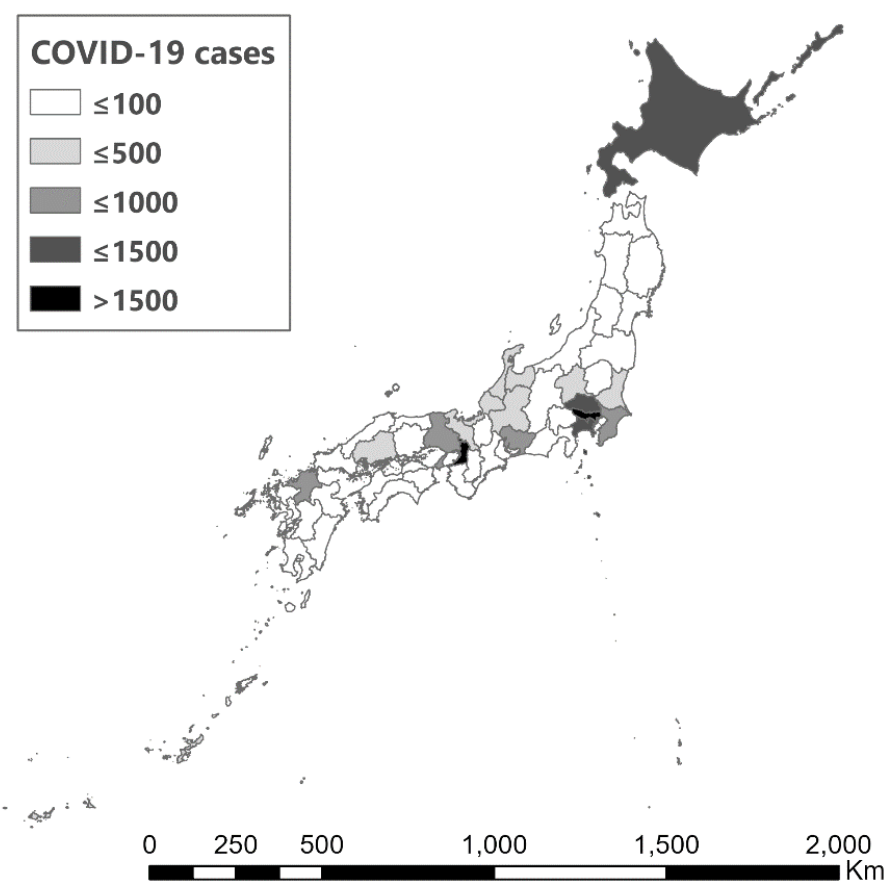

(A)

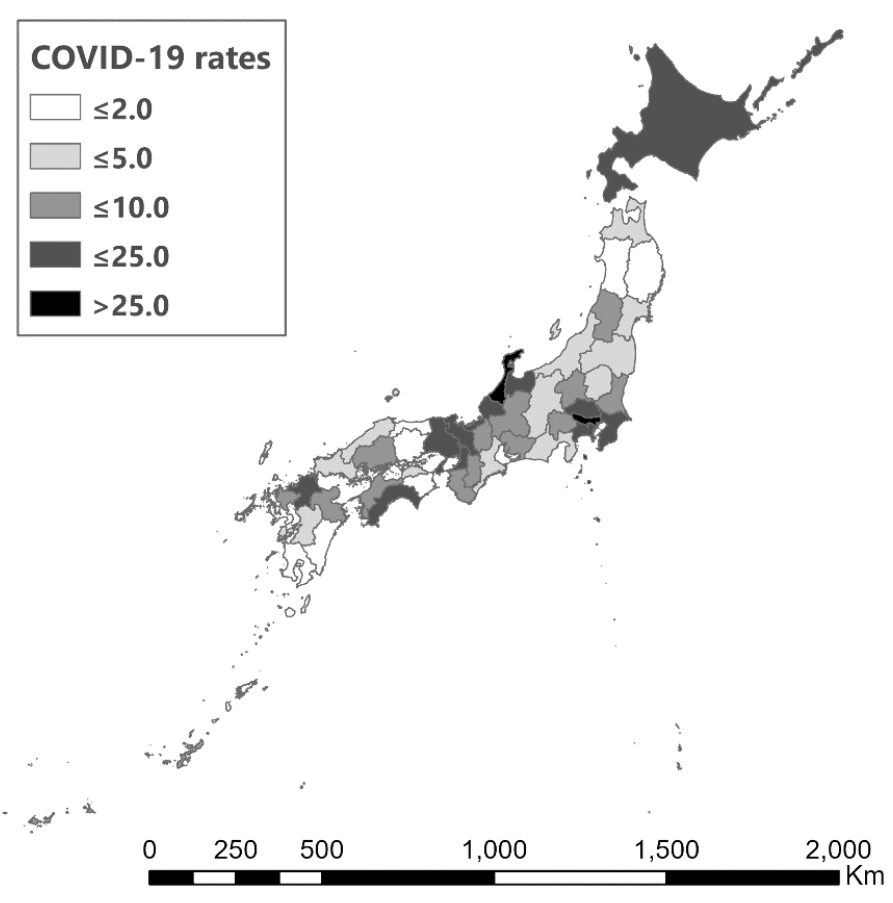

(B)

Figure C1. COVID-19 pandemic by prefecture. (A) Cumulative COVID-19 cases. (B) Cumulative COVID-19 rates per 100,000 people

Data source: Ministry of Health, Labour, and Welfare of Japan 


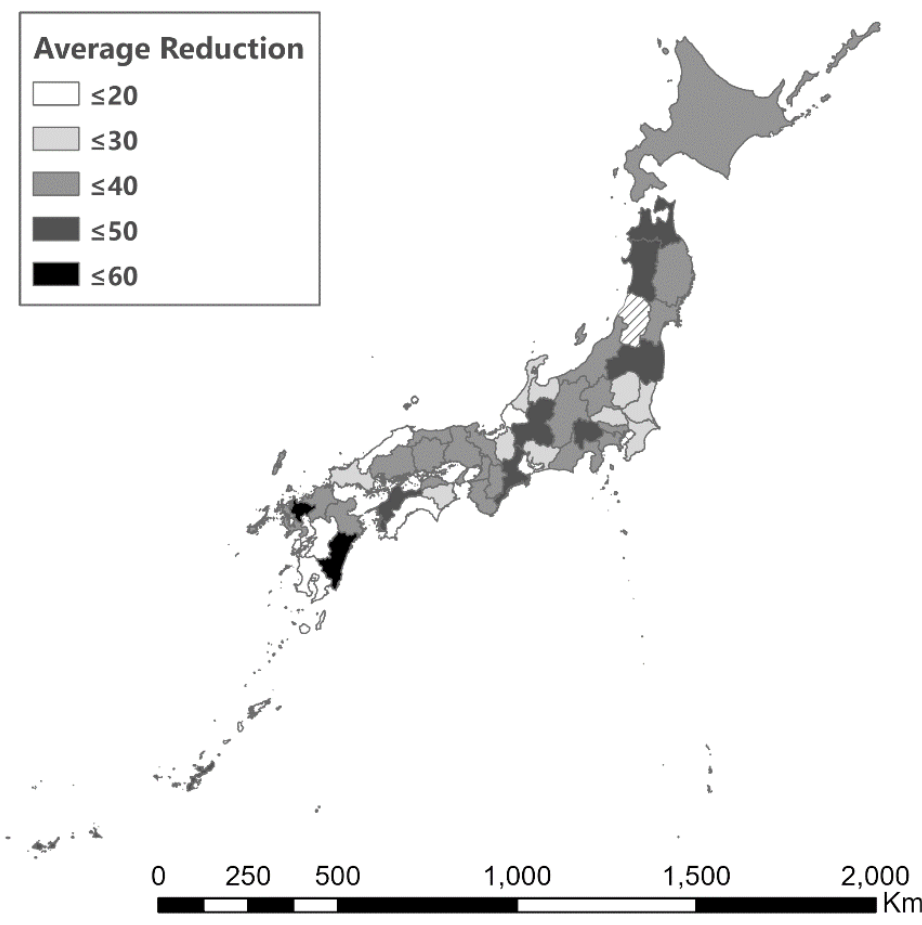

(A)

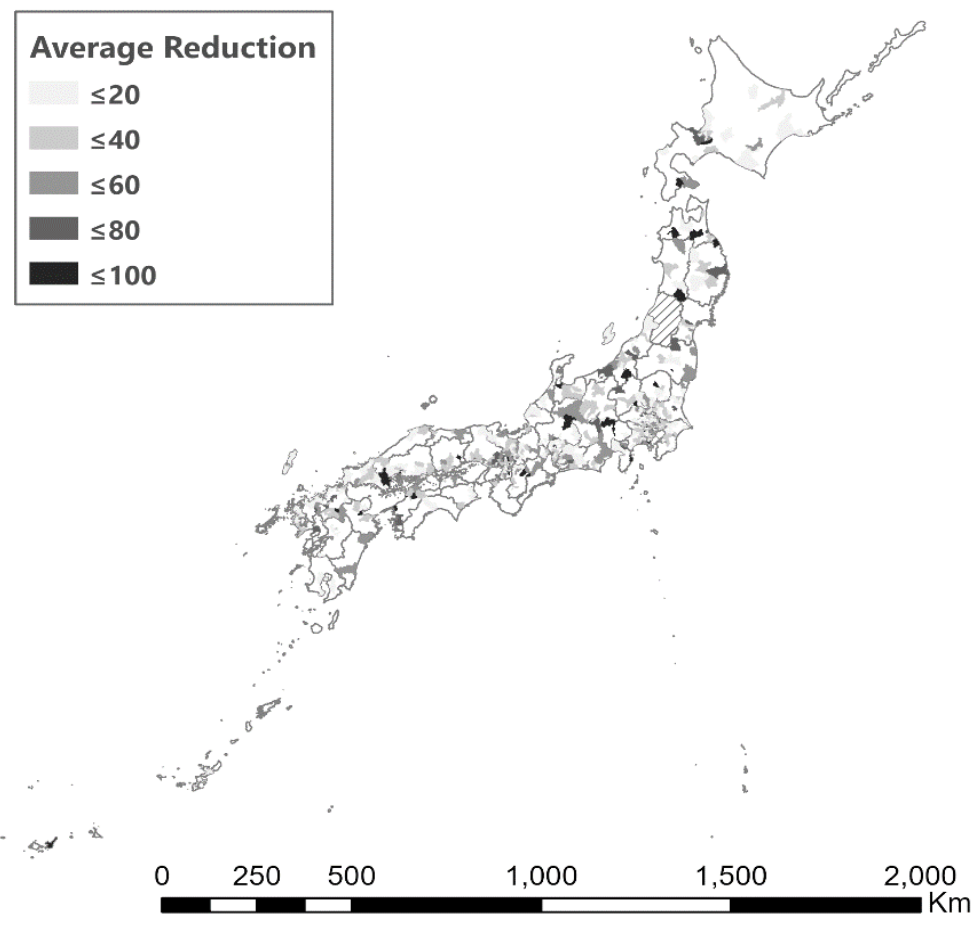

(B)

Figure C2. Average amount of money-burning (A) by prefecture and (B) by city 


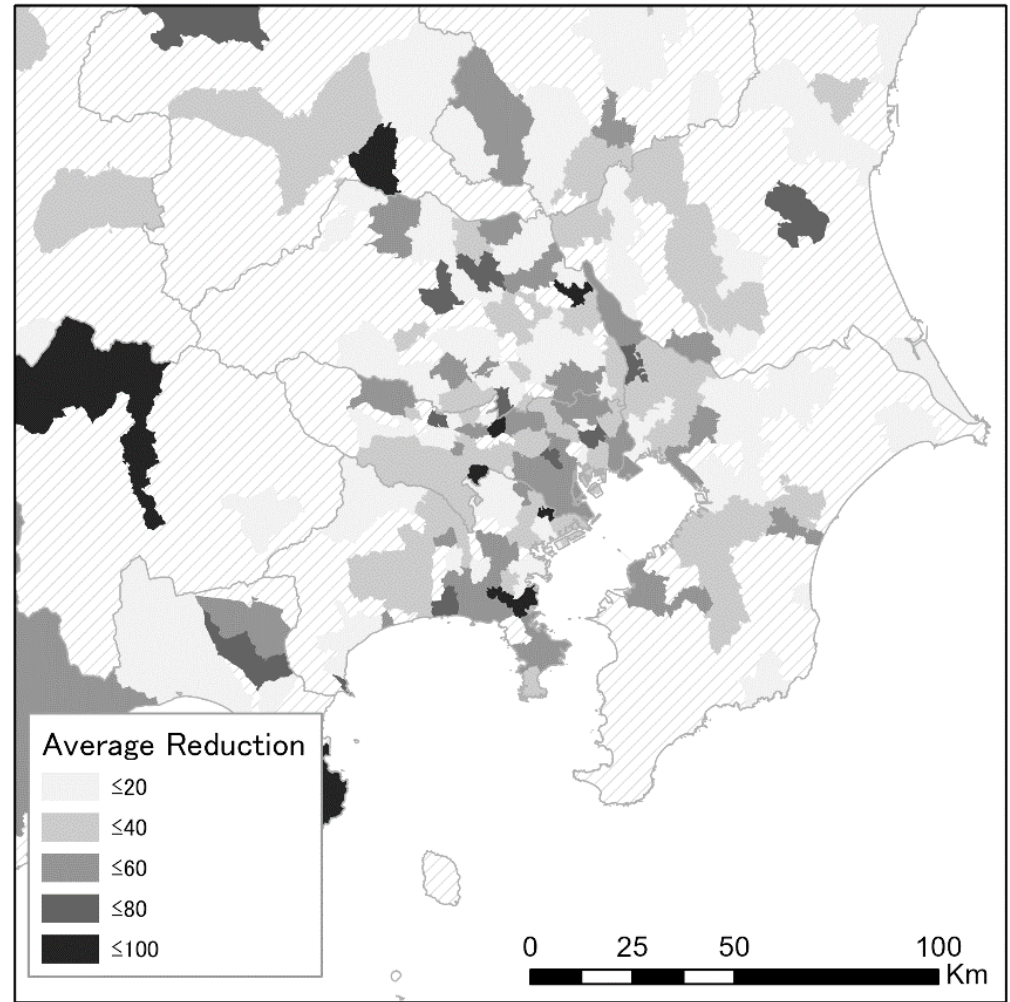

(A)

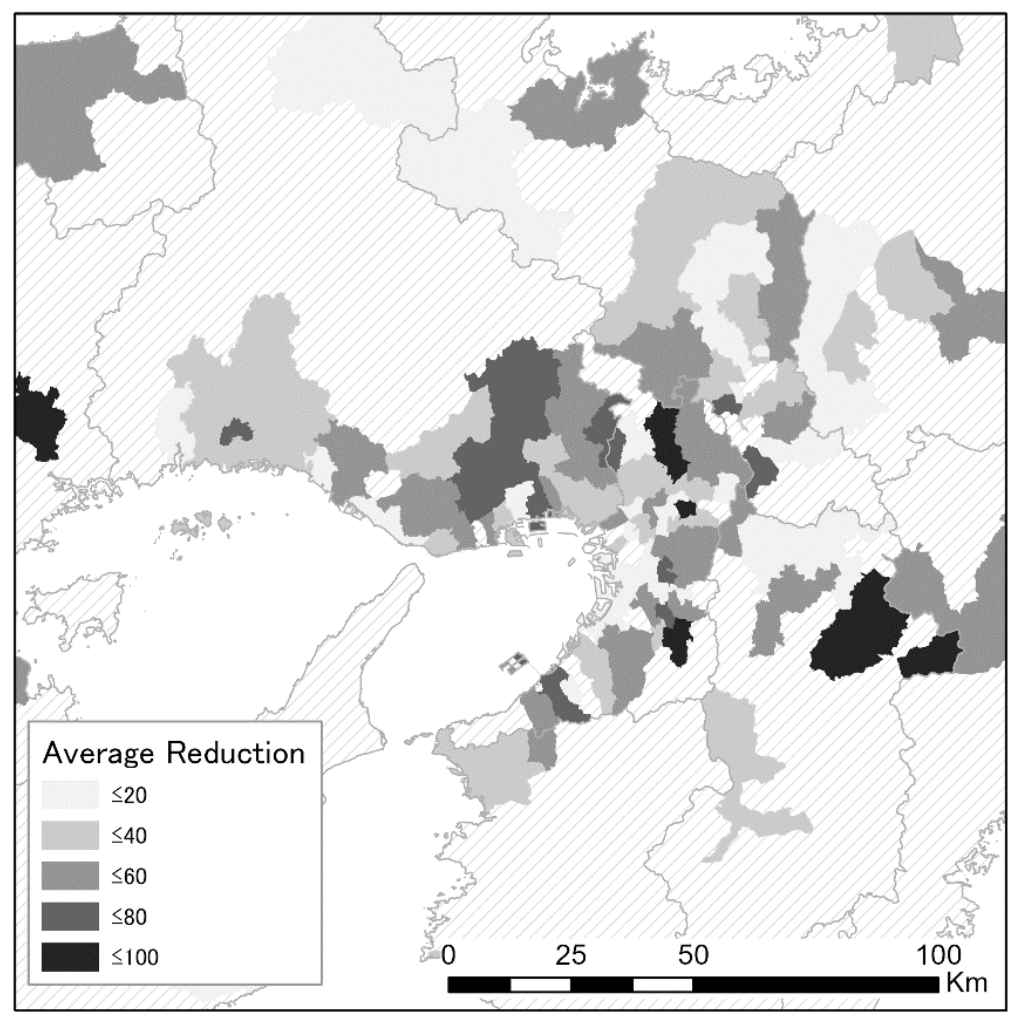

(B)

Figure $\mathrm{C} 3$. Average expenditures from the money-burning in metropolitan areas at the city level. (A) Tokyo. (B) Osaka 
Table C1. Correlation between expenditures from the money-burning and COVID-19 cases at the prefecture level

\section{Cumulative COVID- Cumulative COVID-}
19 cases
19 rates $^{\text {a }}$

(1)

(2)

\begin{tabular}{lll}
\hline Pinball gambling & $0.045^{*}$ & 0.038 \\
Foodservice with alcohol delivery & $0.038^{* * *}$ & $0.056^{* *}$ \\
Foodservice without alcohol delivery & 0.037 & 0.037 \\
Small-scale live music club & $0.044^{*}$ & $0.041^{*}$ \\
Grocery store & $0.052^{* *}$ & $0.057^{* *}$ \\
\hline
\end{tabular}

Note: $*, * *$, and, $* * *$ indicate statistical significance at the $10 \%, 5 \%$, and $1 \%$ levels, respectively a: Cumulative COVID-19 cases per 100,000 people. 